\title{
Hydrogen production by catalytic cracking of methane over nickel gauze under periodic reactor operation
}

\author{
B. Monnerat, L. Kiwi-Minsker, A. Renken* \\ Institute of Chemical Engineering, LGRC-EPFL, CH-1015 Lausanne AG, Switzerland
}

\begin{abstract}
The catalytic cracking of methane over nickel gauze is proposed as an attractive alternative for the production of CO-free hydrogen. The catalyst deactivates due to intensive coke deposition. Therefore, the reactor was operated periodically with the reaction followed by the catalyst regeneration by burning of coke in oxidative atmosphere. The optimal reaction performance was found to consist of reaction periods of 4 min followed by 4 min regeneration periods. (C) 2001 Elsevier Science Ltd. All rights reserved.
\end{abstract}

Keywords: Methane cracking; Hydrogen; Periodic operation; Ni-gauze catalyst

\section{Introduction}

Hydrogen is usually produced by steam reforming, partial oxidation or autothermal reforming of hydrocarbons and alcohols (Jamal \& Wyszynski, 1994). A common drawback of these reactions is the formation of carbon monoxide and carbon dioxide, which are difficult to separate from hydrogen. Moreover, for certain applications, like in fuel cell technology, carbon monoxide has to be removed from hydrogen in order to prevent poisoning of the electro-catalyst. Therefore, the direct catalytic cracking of hydrocarbon into hydrogen and carbon (1) followed by catalyst regeneration in oxidative atmosphere $(2,3)$ is an attractive alternative:

$$
\begin{array}{ll}
\mathrm{CH}_{4} \rightarrow \mathrm{C}+2 \mathrm{H}_{2} & \Delta \mathrm{H}_{298 \mathrm{~K}}^{0}=75 \mathrm{~kJ} / \mathrm{mol}, \\
\mathrm{C}+\frac{1}{2} \mathrm{O}_{2} \rightarrow \mathrm{CO} & \Delta \mathrm{H}_{298 \mathrm{~K}}^{0}=-111 \mathrm{~kJ} / \mathrm{mol}, \\
\mathrm{C}+\mathrm{O}_{2} \rightarrow \mathrm{CO}_{2} & \Delta \mathrm{H}_{298 \mathrm{~K}}^{0}=-283 \mathrm{~kJ} / \mathrm{mol} .
\end{array}
$$

Formation of carbon oxides $\left(\mathrm{CO}_{x}\right)$ can be separated in time from $\mathrm{H}_{2}$ production, since in this case $\mathrm{CO}_{x}$ are formed during the coke removal from the catalytic sur-

\footnotetext{
* Corresponding author. Tel.: + 41-21-693-31-81; fax: + 41-21-69331-90.

E-mail address: albert.renken@epfl.ch (A. Renken).
}

face. An added advantage in two-steps hydrogen production can be gained from heat coupling of endothermic hydrocarbon cracking and exothermic carbon oxidation. In practice it could be, for example, a coaxial reactor operated periodically, so that the heat released during the coke oxidation can be used in situ for the reaction of cracking.

Nickel is known as one of the active catalysts in methane cracking at low temperatures (Zhang \& Amiridis, 1998). Metallic nickel in the form of wire gauze was used in this study. An advantage of the gauze catalyst is the possibility to arrange a structured catalytic bed, characterized by a low-pressure drop during the passage of gases through the reactor. In order to increase the specific surface area of bulk Ni metal, a Raney-type layer was formed on the outer surface of the Ni gauze. This catalyst design combines advantages of metal-gauze structure, high thermo-conductivity of the catalytic bed and high specific surface area of Raney metals.

The objectives of this work were to study the use of periodic operation in a tubular reactor for the catalytic cracking of methane over a nickel wire gauze with the catalyst regeneration via oxidation in oxygen mixture of the deposited coke.

The hydrogen production was optimized as a function of the reaction temperature and the variables of the periodic reactor operation like duration of length of period and cycle split. 


\section{Experimental}

\subsection{Catalyst preparation and characterization}

Ni-gauze (Haver \& Boecker, Germany, purity $\geqslant 99.2 \%$ ) was used for the preparation of the catalyst. The specific surface area of the starting grid material is less than $1 \mathrm{~m}^{2} / \mathrm{g}$, corresponding approximately to the geometrical specific surface. In order to obtain a highsurface area, an Al-Ni alloy was formed on the Ni-gauze surface. Standard procedure of selective Al removal from the alloy by aqueous solution of potassium hydroxide leads to the formation of a outer layer surface with properties of Raney nickel (Wainwright, 1997). The catalyst has a specific area of $26.7 \mathrm{~m}^{2} / \mathrm{g}$ and a mean pore diameter of $\sim 2 \mathrm{~nm}$. The BET specific surface area (SSA) and pore size distribution was measured using $\mathrm{N}_{2}$ adsorption-desorption at $77 \mathrm{~K}$ via Sorptomatic 1990 (Carlo Erba) instrument. A SEM image of the nickel-
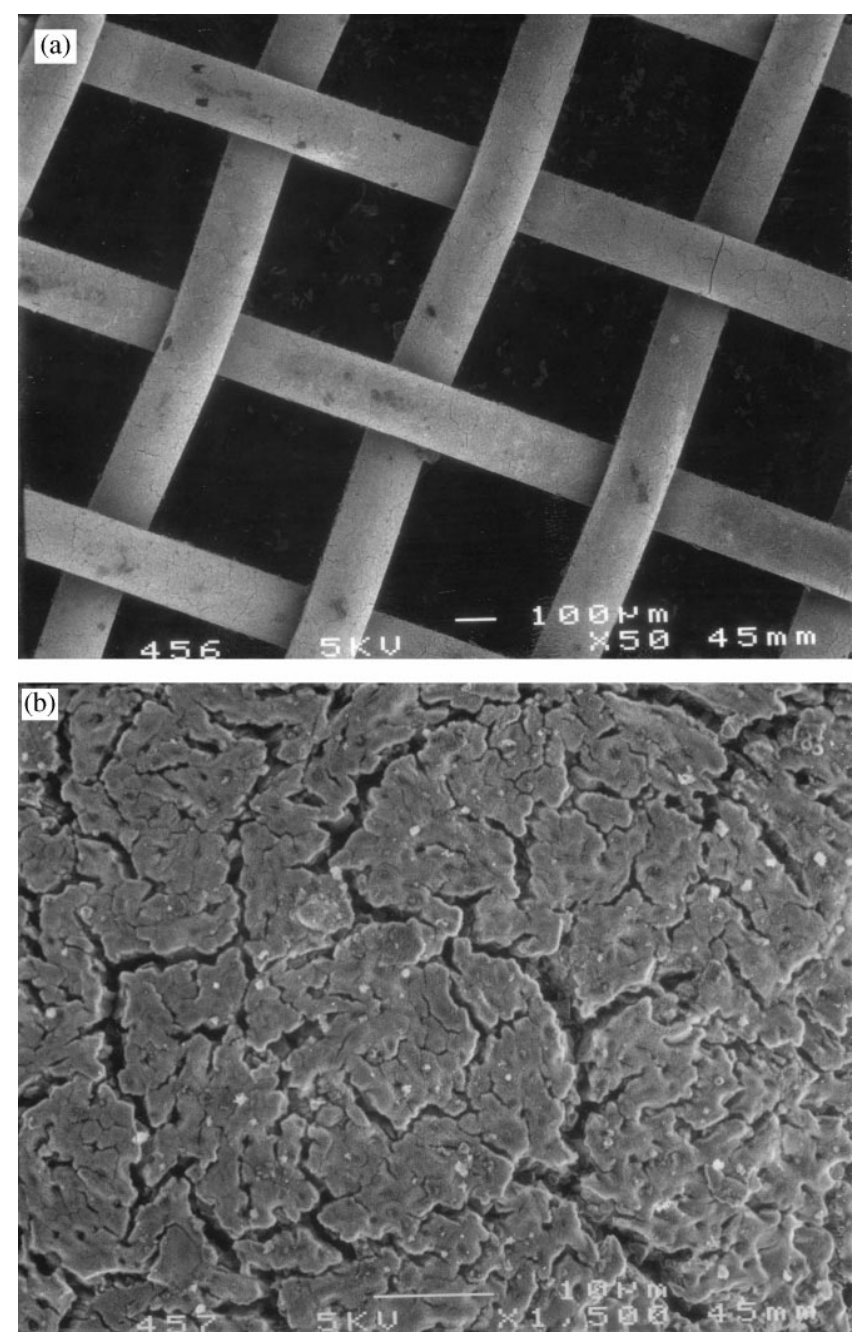

Fig. 1. a and b SEM micrographs of the fresh Ni-gauze catalyst with different magnification. gauze catalyst is shown in Fig. 1a and b with different magnification.

\subsection{Experimental set-up}

The schematic diagram of the experimental set-up is shown in Fig. 2. It consists of two separate gas-feeds converging to a four-way valve, a fixed-bed reactor and an analytical section. Pure gases $\mathrm{CH}_{4}, \mathrm{O}_{2}, \mathrm{H}_{2}$ (>99.99\%) were supplied by Carbagas (Switzerland) and used without further purification. Ar was used as a carrier gas and was purified using a molecular sieve and an oxygen trap.

The gas flow was controlled by mass flow controller (Brooks Instrument B.V., Veenendaal, and Bronkhorst High-Tech B.V., Ruurlo, The Netherlands).

The reaction was carried out in a quartz fixed-bed reactor (internal diameter: $9 \mathrm{~mm}$, length: $200 \mathrm{~mm}$ ) heated by a temperature controlled electric oven. The temperature of the catalyst was measured with two Ktype thermocouples (Philips AG, Dietikon, Switzerland) at two opposite axial points in the bed and their values never differed by more than $2 \mathrm{~K}$. The up-stream and down-stream pressure of the catalytic bed was measured by pressure gauges (Wika AG, Hitzkirch, Switzerland).

The reactor effluents were monitored continuously with a quadrupole mass spectrometer (MS) (type QMG 420, Balzers AG, Principality of Liechtenstein), which was calibrated daily via gas chromatograph (Schimadzu Corporation, Kyoto, Japan) equipped with a Carboxen 1010-Plot column (capillary column, $30 \mathrm{~m}, 0.53 \mathrm{~mm}$ ID, $5 \mathrm{ml} / \mathrm{min}$ Ar, Supelco AG, Switzerland). $\mathrm{CO}$ and $\mathrm{CO}_{2}$ concentrations were monitored by an infrared analyzer (Siemens AG. Karlsruhe).

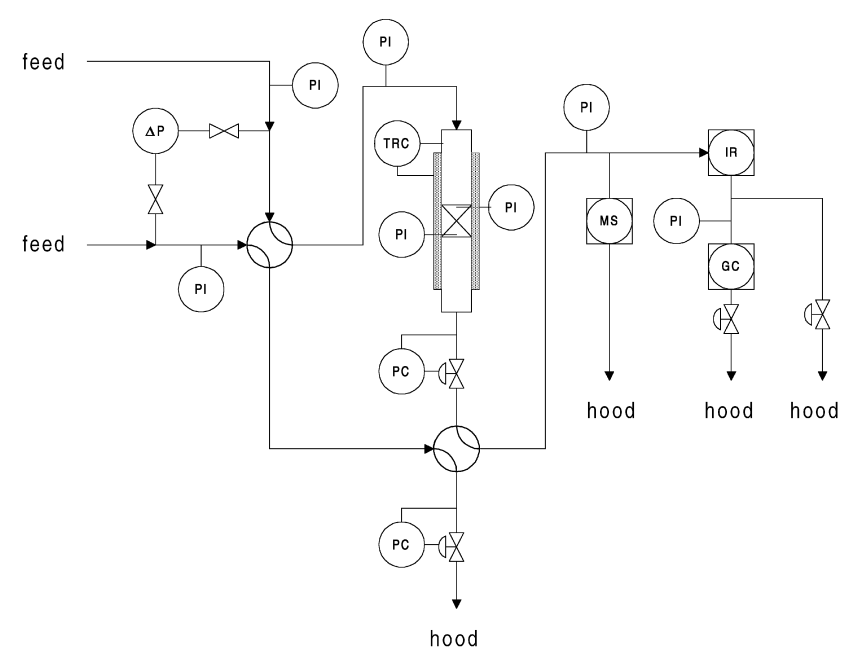

Fig. 2. Schematic diagram of the experimental set-up. Feed: Ar, $\mathrm{CH}_{4}, \mathrm{H}_{2}, \mathrm{CO}, \mathrm{CO}_{2}, \mathrm{O}_{2}, \mathrm{H}_{2} \mathrm{O}, \mathrm{He}$. 


\subsection{Operation conditions}

Experiments were performed with the modified nickel-gauze $(\sim 210 \mathrm{mg})$, introduced in the middle of the reactor in a rolled form (length: $20 \mathrm{~mm}$ ) between two fixed beds consisting of quartz beads (mean diameter: $0.9 \mathrm{~mm}$ ). Residence time distribution experiments showed that its behavior corresponds to a plug-flow reactor. The catalyst was pre-treated in hydrogen flow $\left(y_{112,0}=0.5, Q=150 \mathrm{ml}(\mathrm{NTP}) / \mathrm{min}, p=150 \mathrm{kPa}\right) \quad$ by heating from ambient temperature to $600^{\circ} \mathrm{C}$ at a rate of $5^{\circ} \mathrm{C} / \mathrm{min}$. The $\mathrm{H}_{2}$ feed was then changed to pure Ar, and the temperature of catalyst was set to the desired value. Afterwards, the periodical cracking reaction-catalyst regeneration was started. The inlet partial pressure of methane was $30 \mathrm{kPa}$, the inlet partial pressure of oxygen was $12 \mathrm{kPa}$. The periodic variation of the reactant concentrations in the reactor inlet is presented in Fig. 3a. The reaction starts from the $\mathrm{C}_{\mathrm{CH}_{40}}$ in the reactor input at the first part of a cycle (methane cracking) and is switched to $C_{\mathrm{O}_{2}, 0}$ in the second part of a cycle (catalyst oxidative regeneration). The split between two parts of a period is
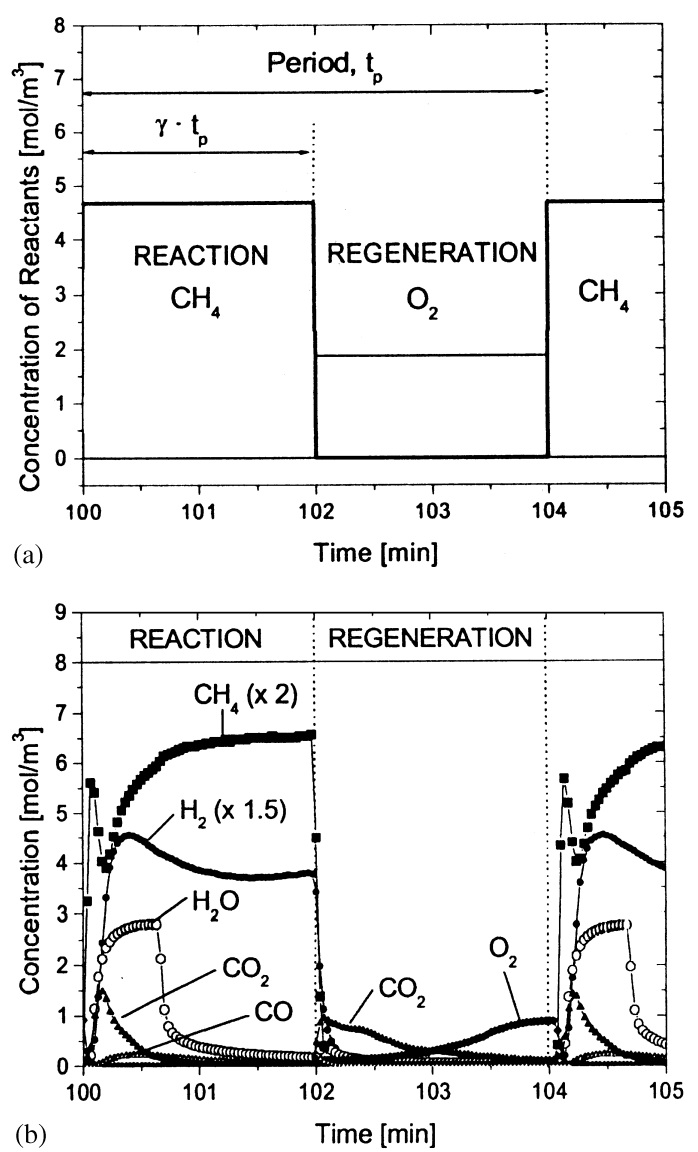

Fig. 3. (a) Variables of the periodic reactor operation: cycle time, $t_{p}$; cycle split, $\gamma$, inlet concentrations $C_{\mathrm{O}_{2.0}} ; C_{\mathrm{CH}_{4,0}}$. (b) Typical transient experiment, $T_{R}=500^{\circ} \mathrm{C} ; Q=75 \mathrm{ml}(\mathrm{NTP}) / \mathrm{min} ; m_{\text {cat }}=207 \mathrm{mg} ; C_{\mathrm{CH}_{4.0}}=$ $4.67 \mathrm{~mol} / \mathrm{m}^{3} ; C_{\mathrm{O}_{2,0}}=1.87 \mathrm{~mol} / \mathrm{m}^{3} ; t_{p}=4 \mathrm{~min} ; \gamma=0.5$. varied by parameter $\gamma$, which presents the ratio of reaction time to period duration. Prior to each new experiment, the catalyst was regenerated by oxidation $\left(y_{\mathrm{O}_{2,0}}=\right.$ $0.08, Q=75 \mathrm{ml}(\mathrm{NTP}) / \mathrm{min}, p=150 \mathrm{kPa})$ at $600^{\circ} \mathrm{C}$ until no $(\mathrm{CO})_{x}$ was detected by analytical devices in the outlet.

The amounts of deposited and burned carbon were calculated from the conversion of methane and the mass balance in carbon oxides formed with the gaseous oxygen.

The time-average conversion of methane was calculated from

$\bar{X}=\frac{\int_{0}^{\gamma-t_{p}} \dot{n}_{\mathrm{CH}_{4,0}} \mathrm{~d} t-\int_{0}^{\gamma-t_{p}} \dot{n}_{\mathrm{CH}_{4, s}} \mathrm{~d} t}{\int_{0}^{\gamma-t_{p}} \dot{n}_{\mathrm{CH}_{4,0}} \mathrm{~d} t}$.

The time-average product selectivity was calculated from Eq. (5), where $v_{i}$ represents the stoichiometric coefficient with values of 2 for hydrogen and water (which correspond the total oxidation of methane) and 1 for carbon oxides:

$\bar{S}_{i, \mathrm{CH}_{4}}=\frac{1}{v_{i}} \frac{\int_{0}^{\gamma-t_{p}} \dot{n}_{i, s} \mathrm{~d} t}{\int_{0}^{\gamma-t_{p}} \dot{n}_{\mathrm{CH}_{4,0}} \mathrm{~d} t-\int_{0}^{\gamma-t_{p}} \dot{n}_{\mathrm{CH}_{4, s}} \mathrm{~d} t}$.

The time-average performance of hydrogen was calculated from

$\bar{L}_{\mathrm{P}, \mathrm{H}_{2}}=\frac{\int_{0}^{\gamma-t_{p}} \dot{n}_{\mathrm{H}_{2, s}} \mathrm{~d} t}{t_{p}}$.

\section{Results and discussion}

\subsection{Catalytic activity and influence of temperature on overall performance}

The methane decomposition over Ni-gauze was studied at different temperatures for a cycle of 4 min with a split of 0.5 , i.e. equal periods of reaction $(2 \mathrm{~min})$ and regeneration $(2 \mathrm{~min})$. For all experiments the only products observed in the gas phase were $\mathrm{H}_{2}, \mathrm{H}_{2} \mathrm{O}, \mathrm{CO}$ and $\mathrm{CO}_{2}$.

A typical example of the gaseous product concentrations in the reactor outlet obtained in a periodic mode with the invariance of the cycle is given in Fig. 3b. It was found that even after 90 min $(25$ cycles $)$ the catalyst activity remained stable.

The time-average methane conversions are shown in Fig. 4 for invariant cycle at different temperatures. The dotted curve in Fig. 4 shows the theoretical (equilibrium) conversion of methane at total pressure $150 \mathrm{kPa}$ with the initial concentration of methane $4.67 \mathrm{~mol} / \mathrm{m}^{3}$, when methane is decomposed into graphite and $\mathrm{H}_{2}$. The experimental results suggest that the carbon formed from methane is thermodynamically less stable than graphite. This observation is in line with the observations reported by Otsuka, Kobayashi, and Takenaka (2000). Fig. 5 presents the mass balance of carbon over the cycle. It is seen 


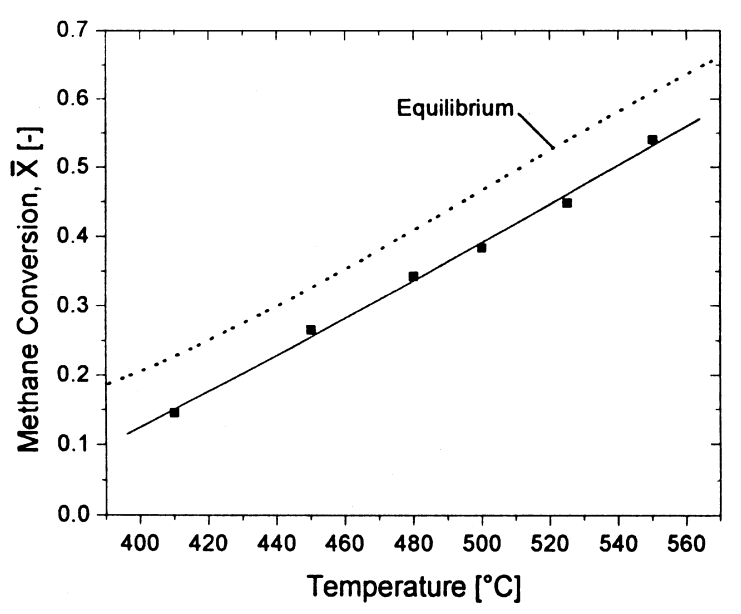

Fig. 4. The methane conversion as a function of temperature: $Q=75 \mathrm{ml}(\mathrm{NTP}) / \mathrm{min} ; m_{\text {cat }}=207 \mathrm{mg} ; C_{\mathrm{CH}_{4,0}}=4.67 \mathrm{~mol} / \mathrm{m}^{3} ; C_{\mathrm{O}_{2,0}}=$ $1.87 \mathrm{~mol} / \mathrm{m}^{3} ; t_{p}=4 \mathrm{~min} ; \gamma=0.5$. The dotted line corresponds to the theoretical (equilibrium) conversion of methane.

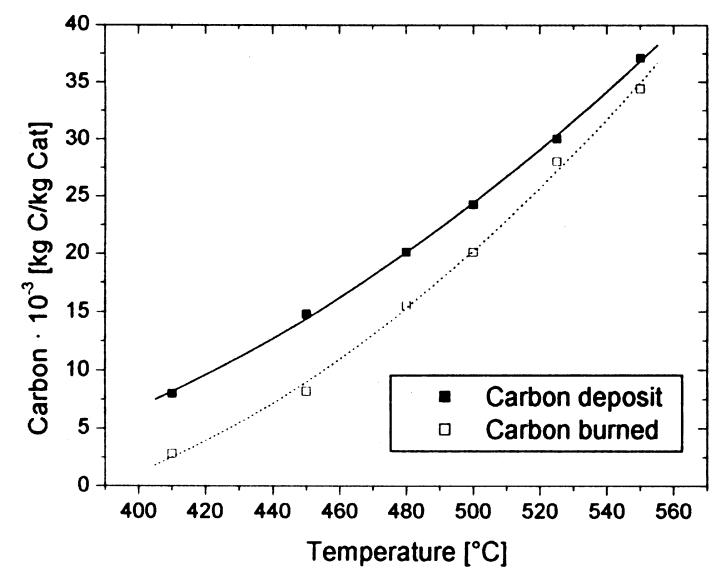

Fig. 5. Mass balance of carbon as a function of temperature. (Same experimental conditions as in Fig. 4).

that the efficiency of regeneration increases with the temperature: at $410^{\circ} \mathrm{C}$ only $35 \%$ of carbon is removed, while at $550^{\circ} \mathrm{C}$ about $95 \%$ of coke is burned. The mass balance of carbon and hydrogen, determined with an experimental error of $\pm 5 \%$, gives the coke composition formula $\mathrm{C}_{n} \mathrm{H}_{m}$. The content of hydrogen in the coke depends on the temperature and influences strongly the conditions of catalyst regeneration since polymeric structures are known to have a low reactivity. The sum of product selectivities containing hydrogen indicates that polymeric structures are formed at temperatures below $450^{\circ} \mathrm{C}$. This observation was also confirmed by the formation of water during the oxidation step. For temperatures higher than $450^{\circ} \mathrm{C}$ no formation of water was observed.

The SEM micrograph of the catalyst after the cracking reaction (Fig. 6) showed the formation of carbon filaments on the catalyst surface. These filaments grow out

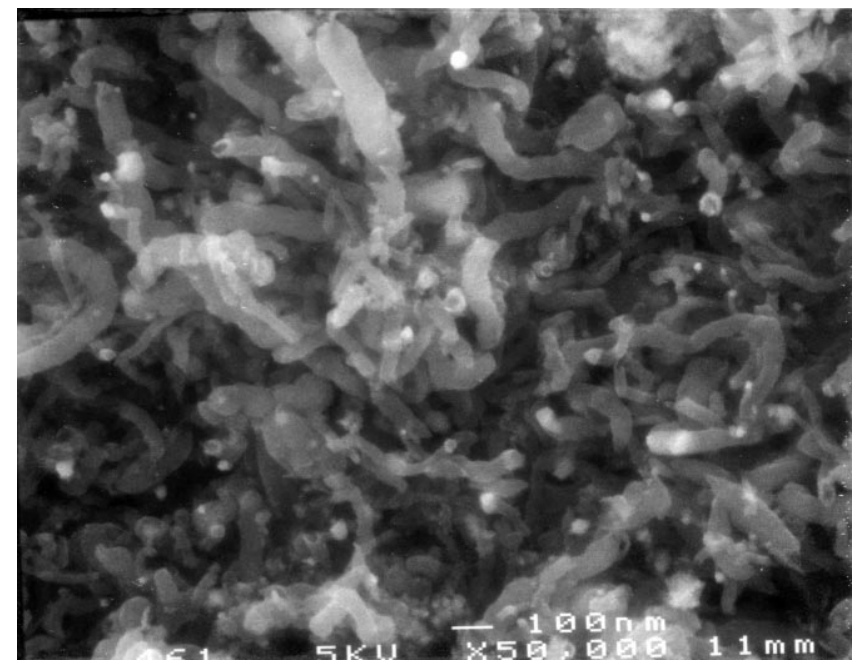

Fig. 6. SEM micrograph (x 50’000) of the nickel gauze catalyst after 25 cycles (invariance of cycle). $m_{\text {cat }}=207 \mathrm{mg} ; Q=75 \mathrm{ml}(\mathrm{NTP}) / \mathrm{min}$; $C_{\mathrm{CH}_{4,0}}=4.67 \mathrm{~mol} / \mathrm{m}^{3} ; C_{\mathrm{O}_{2,0}}=1.87 \mathrm{~mol} / \mathrm{m}^{3} ; t_{p}=4 \mathrm{~min} ; \gamma=0.5$.

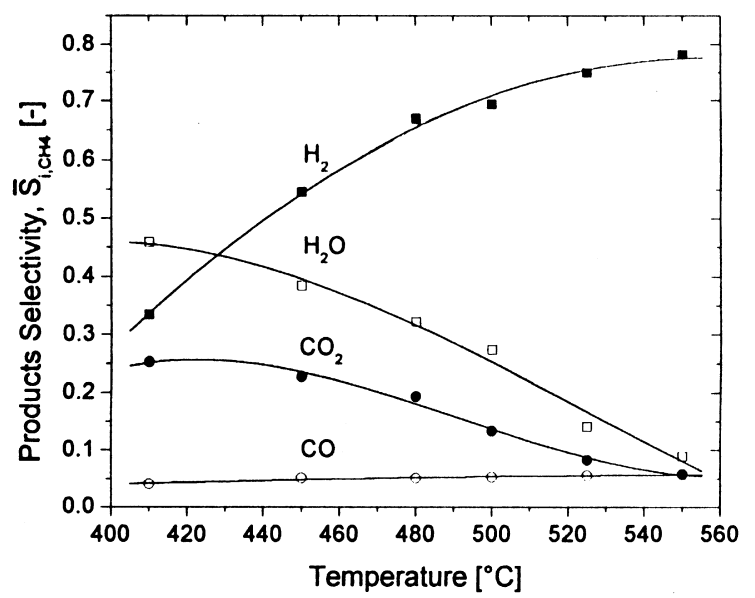

Fig. 7. The product selectivities as a function of temperature $m_{\text {cat }}=207 \mathrm{mg} ; Q=75 \mathrm{ml}(\mathrm{NTP}) / \mathrm{min} ; C_{\mathrm{CH}_{4,0}}=4.67 \mathrm{~mol} / \mathrm{m}^{3} ; C_{\mathrm{O}_{2,0}}=$ $1.87 \mathrm{~mol} / \mathrm{m}^{3} ; t_{p}=4 \mathrm{~min} ; \gamma=0.5$.

of the nickel surface and their length increased with timeon-stream. Each filament was seen to have a bright tip on the top. Zhang and Amiridis (1998) have identified these tips to be Ni particles via SEM/EDS. During the oxidation step, the carbon filaments are burned out and the nickel particles fall on the surface. Some loss of the catalyst (about $10 \%$ of mass after $70 \mathrm{~h}$ on stream) was observed and is assigned due to this coke morphology.

The time-average selectivities of all products, calculated for the reaction part of the cycles, are shown in Fig. 7.

The decomposition of methane leads to the formation of hydrogen as the main product, and water with $\mathrm{CO}_{x}$ as by-products. The hydrogen selectivity was observed to increase monotonously with the temperature and reached a plateau. The water and carbon dioxide 
selectivities decreased with the increase in temperature, because their formations get thermodynamically less favored. The CO selectivity was observed to increase slowly with temperature but was always less than $5 \%$.

The results shown in Figs. 4 and 7 suggest that efficient hydrogen production occurs at temperatures of $540-560^{\circ} \mathrm{C}$. But for the temperatures higher than $500^{\circ} \mathrm{C}$ a hot-spot formation (up to $150^{\circ} \mathrm{C}$ in $20 \mathrm{~s}$ ) was observed during the regeneration step. This process damaged the catalyst leading to crystalline structure modification and a subsequent loss of catalytic activity. Therefore, the temperature of $500^{\circ} \mathrm{C}$ was chosen and kept constant during a preliminary optimization study.

\subsection{Influence of the cycle time}

Figs. $8 \mathrm{a}$ and $\mathrm{b}$ show the transient product concentrations over two cycles with periods of 10 and $20 \mathrm{~min}$. The product transient concentration profiles are similar for the both cycles.

After the switch from oxygen to methane there is a drastic increase of carbon oxides and water concentra-
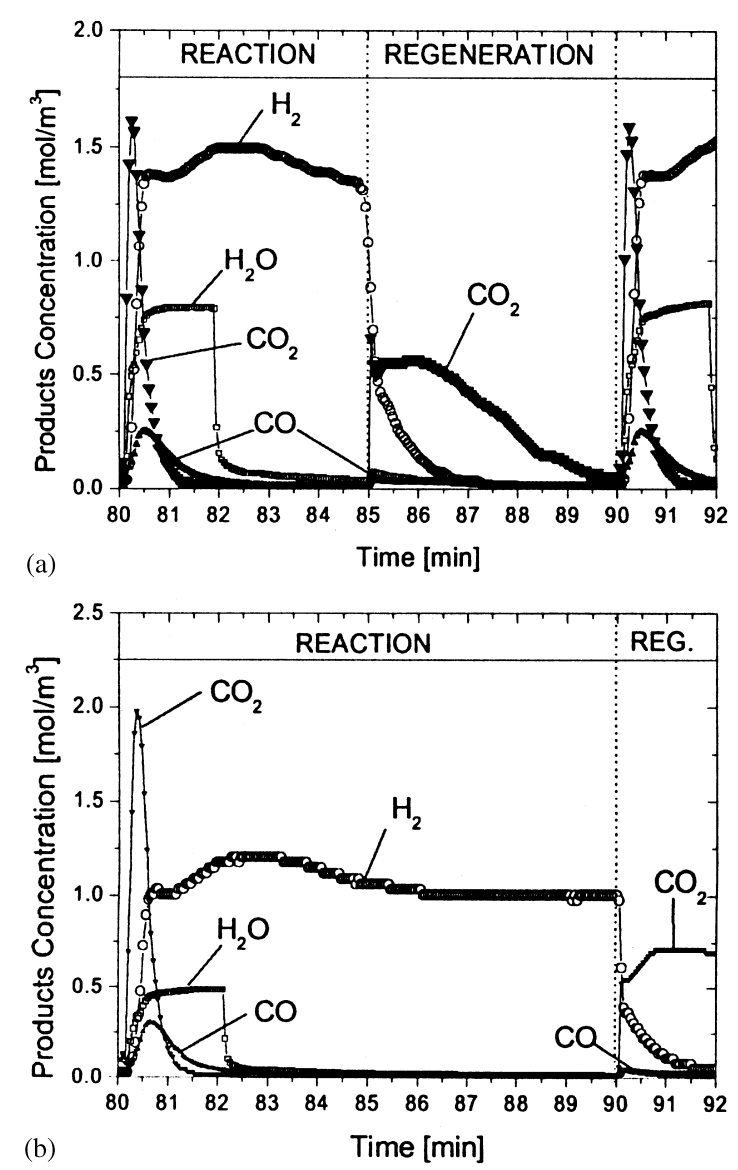

Fig. 8. Transients product concentrations over two cycles during reactor operation with a split $\gamma=0.5$ as a function of cycle time: (a) cycle time $10 \mathrm{~min}$; (b) cycle time $20 \mathrm{~min} ; T_{R}=500^{\circ} \mathrm{C} ; Q=75 \mathrm{ml}(\mathrm{NTP})$ $\min ; m_{\text {cat }}=207 \mathrm{mg} ; C_{\mathrm{CH}_{4.0}}=4.67 \mathrm{~mol} / \mathrm{m}^{3} ; C_{\mathrm{O}_{2.0}}=1.87 \mathrm{~mol} / \mathrm{m}^{3}$. tion. Then their concentrations decline rapidly during the first minute of the cracking reaction. The $\mathrm{CO}_{x}$ decline more rapidly than the concentrations of water and hydrogen.

Nickel oxide is supposed to be formed during the regeneration cycle. Carbon oxides observed at the beginning of the cracking step were produced due to the methane interaction with nickel oxide and oxygen adsorbed on the catalyst surface. The decrease in $\mathrm{CO}$ concentration starts after the decrease of $\mathrm{CO}_{2}$. The lag in $\mathrm{CO}$ formation is due to the reverse water-gas shift or Boudouard reaction. The water produced during the initial period drops quickly to zero after $2 \mathrm{~min}$. This product is mainly formed by the reduction of nickel oxide and of adsorbed oxygen by hydrogen produced during the cracking. For a very long period ( $>16 \mathrm{~min}$ ), the hydrogen concentration attains a quasi steady-state (see Fig. 8b), where the concentrations of water, carbon monoxide and carbon dioxide are very small and can be neglected.

The quantify the amount of oxygen present on the catalyst surface after the regeneration step, several experiments were carried out using pulse reduction of nickel catalyst after different times of exposure to oxygen. The results are presented in Fig. 9 showing that a maximal capacity of oxygen storage corresponds to about $1.2 \mathrm{~mol} \mathrm{O}_{2} / \mathrm{kg}_{\text {cat }}$.

The results of this study are in line with the results reported by Zhang and Amiridis (1998) and Otsuka et al. (2000). These authors reported the decomposition of methane on the supported $\mathrm{Ni} / \mathrm{SiO}_{2}$ catalyst. But contrary to us, the catalyst regeneration took place after 150 or $200 \mathrm{~min}$ and the formation of by-products was not detected. To determine if by-products are formed by gaseous or surface oxygen, several experiments were carried out purging the reactor with argon (during $2 \mathrm{~min}$ ) between the oxidation and the cracking period. The product distribution was found to be the same with and without Ar.

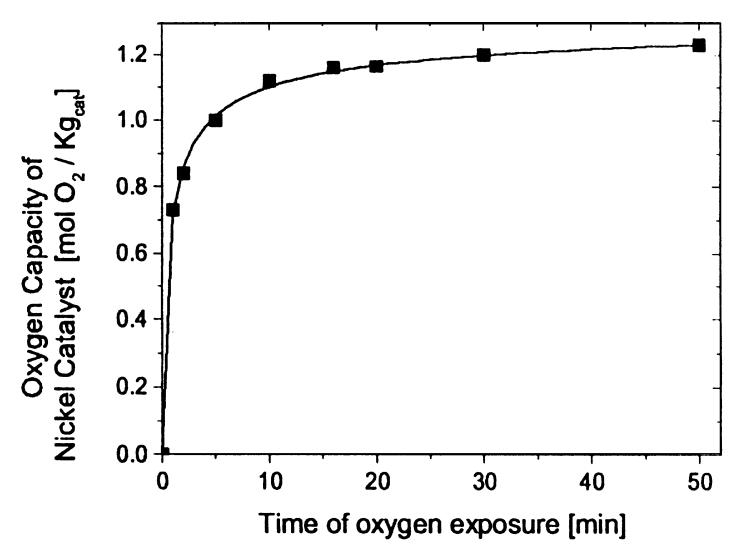

Fig. 9. Reduction of Ni-catalyst after exposure to $\mathrm{O}_{2}$ at different time: $m_{\text {cat }}=207 \mathrm{mg} ; Q=75 \mathrm{ml}(\mathrm{NTP}) / \mathrm{min} ; C_{\mathrm{O}_{2,0}}=1.87 \mathrm{~mol} / \mathrm{m}^{3} ; T=500^{\circ} \mathrm{C}$. 
Therefore, it is highly probable that water and carbon oxides produced during the first 1-2 min after switching from oxygen to methane are formed by the oxygen from nickel oxide and chemisorbed during the regeneration step.

The dependence of the time-average methane conversion and the product selectivities on the cycle duration is shown on Fig. 10. Methane conversion decreases as the cycle period increased, due to the catalyst deactivation. When the period increased, the hydrogen selectivity increases monotonously up to a plateau of $90 \%$. The selectivity of water goes down with the increased cycle time since the conversion of methane decreases and less hydrogen is produced. The selectivities of carbon dioxide $(15 \%)$ and carbon monoxide $(5 \%)$ did not depend on the cycle time.

The time-average hydrogen performance was studied as a function of cycle time and is presented in Fig. 11. It shows a maximum for a 4 min cycle. At longer cycles the

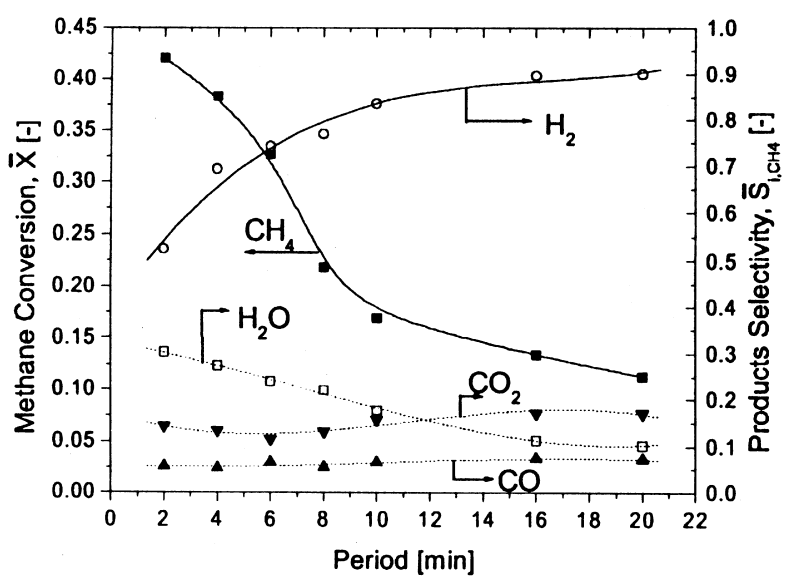

Fig. 10. The time-average methane conversion and product selectivities as a function of cycle period. $T_{R}=500^{\circ} \mathrm{C} ; Q=75 \mathrm{ml}(\mathrm{NTP}) / \mathrm{min}$; $m_{\text {cat }}=207 \mathrm{mg} ; C_{\mathrm{CH}_{4,0}}=4.67 \mathrm{~mol} / \mathrm{m}^{3} ; C_{\mathrm{O}_{2.0}}=1.87 \mathrm{~mol} / \mathrm{m}^{3} ; \gamma=0.5$.

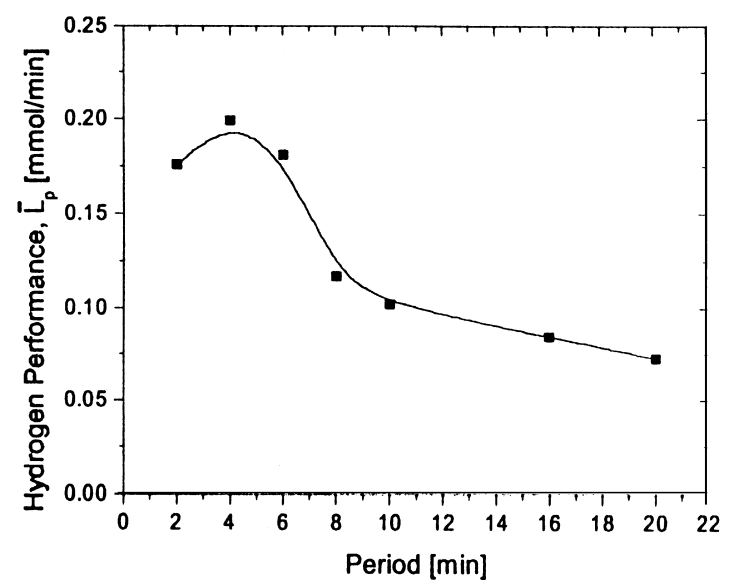

Fig. 11. The time-average hydrogen performance as a function of cycle time. $T_{R}=500^{\circ} \mathrm{C} ; Q=75 \mathrm{ml}(\mathrm{NTP}) / \mathrm{min} ; m_{\text {cat }}=207 \mathrm{mg} ; C_{\mathrm{CH}_{4.0}}=$ $4.67 \mathrm{~mol} / \mathrm{m}^{3} ; C_{\mathrm{O}_{2,0}}=1.87 \mathrm{~mol} / \mathrm{m}^{3} ; \gamma=0.5$. conversion is lower but the selectivity is higher and inversely for shorter cycles. The hydrogen selectivity is the most important characteristic for some niche applications of hydrogen production by cracking, such as use in fuel cells. Therefore, a compromise between the performance and selectivity towards hydrogen was chosen at cycle time of $8 \mathrm{~min}$ and conduct through the further study of optimization of the reaction conditions.

\subsection{Influence of the cycle split}

The influence of the cycle split on the time-average methane conversion and on the product selectivity, for a cycle period of $8 \mathrm{~min}$ is shown in Fig. 12. When the split is increased, the methane conversion decreases regularly. Increasing the split implicates a lowest efficiency of the coke oxidation since the catalyst surface is not fully reoxidized. The hydrogen selectivity increases monotonously when the methane exposure duration increases and then reached a plateau. The carbon dioxides time-average selectivity goes down with the increasing of the split value. This diminution is caused by the decrease in the amount of oxygen adsorbed on the surface. The selectivity of carbon monoxide remains constant except for the shortest exposure of oxygen where it drops to a value of $2 \%$.

The time-average hydrogen performance (Fig. 13) shows a maximum for a split value of 0.5. It corresponds to a symmetric period when the time of cracking is equal to the time of regeneration. An explanation of this observation is probably due to the same reaction rate of methane cracking and coke oxidation. It could be expected if the rate-determining step is the diffusion of carbon through the metal. Formation of carbon filaments as a result of hydrocarbons cracking of higher molecular weight has been reported in the literature (Snoeck \& Froment, 1997a,b; Bartholomew, 1982, Trimm, 1977 and references within). The catalysts studied were supported metals like nickel, iron, cobalt, and

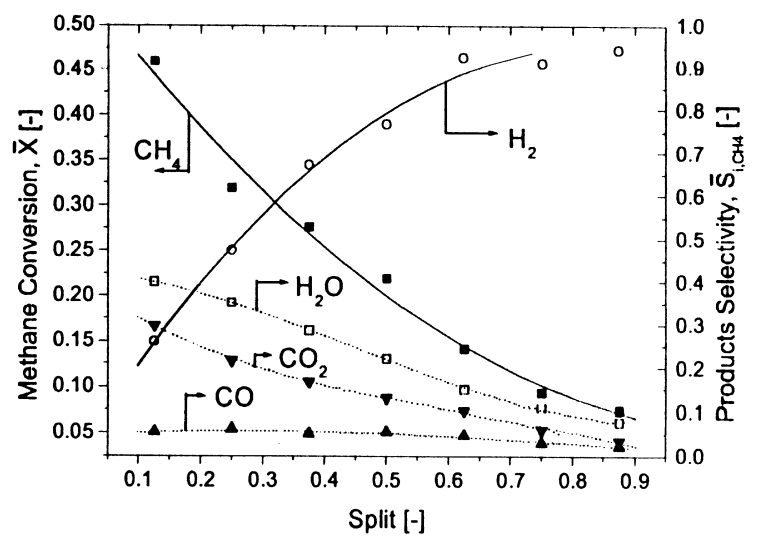

Fig. 12. The time-average methane conversion and products selectivity as function of cycle split. $T_{R}=500^{\circ} \mathrm{C} ; Q=75 \mathrm{ml}(\mathrm{NTP}) / \mathrm{min} ; m_{\text {cat }}=$ $207 \mathrm{mg} ; C_{\mathrm{CH}_{4.0}}=4.67 \mathrm{~mol} / \mathrm{m}^{3} ; C_{\mathrm{O}_{2,0}}=1.87 \mathrm{~mol} / \mathrm{m}^{3} ; t_{p}=8 \mathrm{~min}$. 


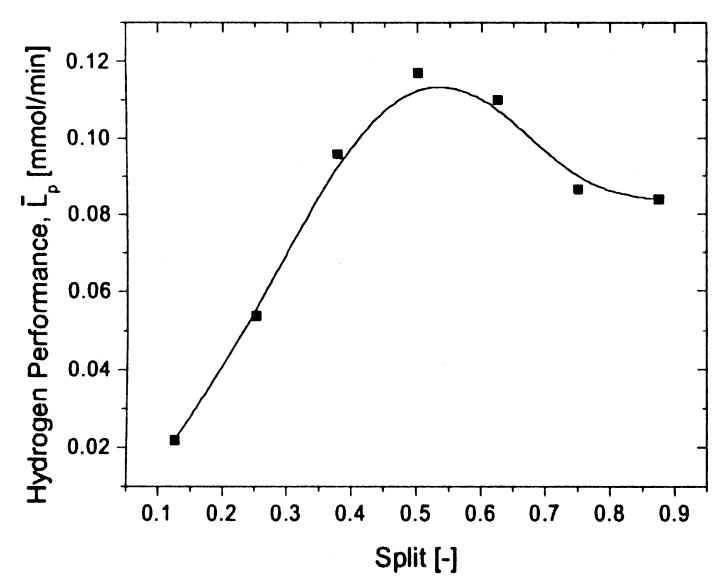

Fig. 13. The time-average hydrogen performance as function of cycle split. $T_{R}=500^{\circ} \mathrm{C} ; Q=75 \mathrm{ml}(\mathrm{NTP}) / \mathrm{min} ; m_{\text {cat }}=207 \mathrm{mg} ; C_{\mathrm{CH}_{4.0}}=$ $4.67 \mathrm{~mol} / \mathrm{m}^{3} ; C_{\mathrm{O}_{2,0}}=1.87 \mathrm{~mol} / \mathrm{m}^{3} ; t_{p}=8 \mathrm{~min}$.

several alloys. A common mechanism of filament growth consists of carbon species formation on the outer surface of the metal, carbon dissolution in the metal, diffusion through the metal and precipitation from the metal at the near surface for the formation of the filament body.

\section{Conclusions}

The direct catalytic cracking of methane into hydrogen and carbon was explored in detail as a potential alternative to steam reforming and partial oxidation to produce hydrogen free of carbon oxides. The Ni-grid with Raneytype outer layer was shown to be active for this reaction at relatively low temperatures of $450-500^{\circ} \mathrm{C}$. Deactivation of the catalyst occurs through the coke deposition in the form of filamentous carbon as shown by SEM. Deactivated catalyst can be regenerated in the oxidative atmosphere. Therefore, the direct catalytic cracking was followed by catalyst regeneration during periodic reactor operation.

The temperature strongly affects the conversion and the selectivity of the process towards hydrogen and carbon oxides formations. The influence of cycle time on the time-average hydrogen performance shows a maximum for a cycle of $4 \mathrm{~min}$. The selectivity of carbon oxides are not influenced by the cycle duration. The influence of the cycle split on the time-average hydrogen performance shows that a maximum value is attained $\gamma=0.5$. This value corresponds to a symmetric period when the time of cracking is equal to the time of regeneration.

\section{Notation}

BET Brunauer, Emmet, Teller

C gas-phase concentration, $\mathrm{mol} / \mathrm{m}^{3}$

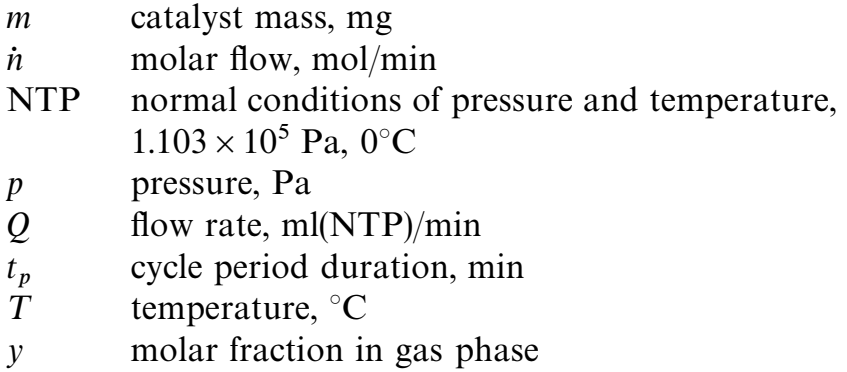

Greek letter

$\gamma \quad$ cycle split, dimensionless

\section{Subscripts}

$0 \quad$ at reactor inlet

cat catalyst

$i \quad$ products

$R \quad$ reactor

$S \quad$ at reactor outlet

\section{Acknowledgements}

The authors gratefully acknowledge the help of B. Senior for the SEM images, I. Yuranov and E. Casali for the catalysts preparation and characterization, the Swiss National Science Foundation for the financial support.

\section{References}

Bartholomew, C. H. (1982). Carbon deposition in steam reforming and methanation. Catalysis reviews, Science and Engineering, 24(1), $67-112$ and references within.

Jamal, Y., \& Wyszynski, M.-L. (1994). On-board generation of hydrogen-rich gaseous fuels - a review. International Journal of Hydrogen Energy, 19(7), 557-572.

Otsuka, K., Kobayashi, S., \& Takenaka, S. (2000). Decomposition and regeneration of methane in absence and the presence of a hydrogen-adsorbing alloy $\mathrm{CaNi}_{5}$. Applied Catalysis, 190 , 261-268.

Snoeck, J.-W., \& Froment, G. F. (1997a). Filamentous carbon formation and gasification: Thermodynamics, driving force, nucleation and steady state growth. Journal of Catalysis, 169, 240-249.

Snoeck, J.-W., \& Froment, G. F. (1997b). Kinetic study of the carbon filament formation by methane cracking on a Ni catalyst. Journal of Catalysis, 169, 250-262.

Trimm, D. L. (1977). The formation and removal of coke from nickel catalyst. Catalysis reviews, Science and Engineering, 16(2), 155-189, and references within.

Wainwright, M. S. (1997). Skeletal metal catalysts. Handbook of heterogeneous catalysis vol. 1 (pp. 64-72).

Zhang, T., \& Amiridis, M.-D. (1998). Hydrogen production via the direct cracking over silica-supported nickel catalysts. Applied Catalysis, 167, 161-172, and references within. 